\title{
Using Induced Fuzzy Bi-Model to Analyze Employee Employer Relationship in an Industry
}

\author{
Dhrubajyoti Ghosh \\ Department of Mathematics \\ National Institute of Technology, Durgapur \\ Durgapur, India
}

\author{
Anita Pal \\ Department of Mathematics \\ National Institute of Technology, Durgapur \\ Durgapur, India
}

\begin{abstract}
The employee-employer relationship is an intricate one. In an industry, the employers expect to achieve performances in quality and production in order to earn profit, on the other side employees need good pay and all possible allowances and best advantages than any other industry. Our main objective of this paper is to analyze the relationship between employee and employer in workplace and discussed how to maintain a strong employee and employer relationship which can produce the ultimate success of an organization using Induced Fuzzy bi-model called Induced Fuzzy Cognitive Relational Maps (IFCRMs). IFCRMs are a directed special fuzzy digraph modelling approach based on expert's opinion. This is a non statistical approach to study the problems with imprecise information.
\end{abstract}

Keywords-Fuzzy Cognitive Map; Fuzzy Relational Maps; Fuzzy Cognitive Relational Maps; Induced Fuzzy Cognitive Relational Maps; Fuzzy bi-model; employee employer relationship

\section{INTRODUCTION}

The fuzzy model is a finite set of fuzzy relations that form an algorithm for determining the outputs of a process from some finite number of past inputs and outputs. Fuzzy model can be used in applied mathematics, to study social and psychological problem and also used by doctors, engineers, scientists, industrialists and statisticians. Fuzzy models are mathematical tools introduced by L.A. Zadeh (1965). Later Politician scientist Axelord (1976) used this fuzzy model Coginitive Maps (CMs) to study decision making in social and political systems. CMs are signed digraphs designed to represent causal assertion and belief system of a person (or group of experts) with respect to a specific domain, and use that statement in order to analyze the effect of a certain choice on a particular objective.

Using the concepts of neural networks and fuzzy logical approach Bart Kosko (1986) proposed some models which extend the idea of Cognitive Maps by allowing the concepts to be represented linguistically with an associated fuzzy set. These models are well suited to get a clear representation of the knowledge to support decision making process and assist in the area of computational intelligence, which involves the application of soft computing methodologies even though the given inputs are vague, uncertain and even contradictory in nature. There are various types of fuzzy models like Fuzzy Cognitive Maps (FCMs), Fuzzy Relational Maps (FRMs), Fuzzy Relational Equations (FREs), Induced Fuzzy Cognitive Maps (IFCMs). Those models plays a vital role in several real world data problems like various infectious diseases problems (cancer, tuberculosis, migration etc.), student life in rural area, problems of private employees in their day to day life, effects of social networks on children's daily life etc. In this paper we use fuzzy bi-model called Induced Fuzzy Cognitive Relational Maps (IFCRMs) which is a directed bi-graph with concepts like policies, events, etc. as nodes and causalities as edges. It represents causal relationship between concepts. This fuzzy bimodel studied various social problems. Among these problems we are going to discuss about a particular one. Recent years deals with one of the key human resources (HR) issues in current working life, namely employee relations. Employee relations is a term used to describe a company's efforts to prevent and resolve problems arising from situations at work. In this paper we have focused on employee relation programs and its essential elements which increase employee satisfaction and good morale among workers. Happy workers are more productive, and more productive means a better bottom line for an industry. This paper have organized in nine section. Section one contains introduction. Section two represents basic definition of FCMs and FRMs models. Section three describes about fuzzy bi-model method. Section four gives the idea of FCRMs. Section five gives the mathematical approach of FCRMs of discussed problems. Section six gives the idea of IFCRMs. Section gives the mathematical approach of IFCRMs of discussed problems. Section eight describes the difference between FCRMs and its induced form IFCRMs. Section nine conclusions based on our study.

\section{FUZZY MAPPING}

Before the discussion of FCMs we describe about the CMs. CMs were introduced by Axelord (1976), in order to develop and study social scientific knowledge in the field of decision making in activities related to international politics. CMs are signed digraphs designed to represent causal assertion and belief system of a person (or group of experts) with respect to a specific domain, and use that statement in order to analyze the effect of a certain choice on particular objectives.

\section{A. Fuzzy Cognitive Maps}

Fuzzy Cognitive Maps (FCMs) introduced by Kosko (1986) extend the idea of Cognitive Maps by allowing the concepts to be represented linguistically with an associated fuzzy set. FCMs are fuzzy signed digraph with feedback (Kosko, 1986, 1988). It represents causal relationship between concepts. FCMs list the fuzzy rule or causal flow paths that relate events. 


\section{B. Formation of FCMs}

If increase in one concept or node leads to increase in another concepts, we assign the value 1 and for decreasing we assign the value -1 . If there exists no relation between concepts the value 0 is given. Consider the $C_{1}, C_{2}, \ldots \ldots, C_{n}$ be the nodes of the FCM. Suppose the directed graphs drawn using edge weight $e_{i j} \in\{0,1,-1\}$. The Matrix $\mathrm{E}$ be defined by $E=\left(e_{i j}\right)$ where $e_{i j}$ is the weight of the directed edge $C_{i} C_{j}$. E is called adjacency matrix of the FCM. All matrices associated with an FCM are always square matrices with diagonal entries as zero. Now

- The instantaneous state vector $A=\left(a_{1}, a_{2}, \ldots, a_{n}\right)$ where $a_{i} \in\{0,1\}$, and it denotes the ON-OFF position of the node at an instant; $a_{i}=0$ if $a_{i}$ is off and $a_{i}=1$ if $a_{i}$ is on for $i=1,2, \ldots, n$.

- Let $C_{1} C_{2}, C_{2} C_{3}, \ldots, C_{i} C_{j}$ be the nodes of the edge of the FCM $(i \neq j)$ form a directed cycle and FCM is said to be cyclic if it possesses a directed cycle. Otherwise it is acyclic.

- FCM with cycles is said to have a feedback. when there is a feedback in an FCM, i.e., when the causal relations flow through a cycle in a revolutionary way, the FCM is called dynamical system.

- When node $C_{\mathrm{i}}$ switched on and if the causality flows through the edges of a cycle and if it again caused $C_{\mathrm{i}}$, we say that dynamical system goes round and round where $i=1,2, \ldots, n$.

- The equilibrium state for this dynamical system is called hidden pattern.

- If the equilibrium state of a dynamical system is a unique state vector, then is called fixed point.

- If the FCM settles down with a state vector repeating in the form $A_{1} \rightarrow A_{2} \rightarrow \ldots \ldots \rightarrow A_{i} \rightarrow A_{1}$, then this equilibrium is called a limit cycle.

- Finite number of FCMs can be combined together to produce the joint effect of all the FCMs with nodes i.e. Combined FCMs denotes the relational matrix by $E=E_{1}+E_{2}+\cdots+E_{p}$.

- Suppose $A=\left(a_{1}, \ldots, a_{n}\right)$ is a vector which is passed into a dynamical system E. Then $A E=\left(a_{1}^{\prime}, \ldots, a_{n}^{\prime}\right)$ after thresholding and updating the vector suppose we get $\left(b_{1}, \ldots, b_{n}\right)$.We denote that by $\left(a_{1}^{\prime}, \ldots, a_{n}^{\prime}\right)$ $\Leftrightarrow\left(b_{1}, \ldots, b_{n}\right)$. Thus the symbol $\Leftrightarrow$ means the resultant vector has been threshold and updated.

\section{Definition of Fuzzy Relational Maps}

Fuzzy Relational Maps (FRMs) are a directed graph or a map from domain space to range space with concepts and causalities as edges.

Let,

Domain space $=n$

Range space $=m \quad[m \neq n]$

$R_{1}, R_{2}, \ldots, R_{m}$ be the nodes of range space.
$R=\left\{\left(x_{1}, x_{2}, \ldots . ., x_{m}\right) \mid x_{j}=0\right.$ or 1$\} \forall j=1,2 \ldots ., m$.

if $x_{j}=1$ i.e. $R_{j}$ is on state

else $x_{j}=0$ i.e. $R_{j}$ is off state

Similarly,

$D_{1}, D_{2}, \ldots ., D_{n}$ be the nodes of domain space.

$D=\left\{\left(x_{1}, x_{2}, \ldots . ., x_{n}\right) \mid x_{i}=0\right.$ or 1$\} \forall i=1,2 \ldots, n$.

if $x_{i}=1$ i.e. $D_{i}$ is on state

else $x_{i}=0$ i.e. $D_{i}$ is off state.

\section{Formation of FRMs}

Let $D_{i}$ and $R_{j}$ denotes the two nodes of FRMs. $e_{i j}$ be the weight of the edge $D_{i} R_{j}$ (or $R_{j} D_{i}$ ), then $e_{i j} \in\{0,1,-1\}$ The relational matrix $E$ be defined as $E=\left(e_{i j}\right)$.

- Let $A=\left(a_{1} \ldots, a_{n}\right), a_{i} \in\{0,1\}$ where $i=1,2, \ldots, n$. $\mathrm{A}$ is called the instantaneous state vector of the domain space and it denotes the on-off position of the nodes at any instant i.e. $a_{i}=0$ if $a_{i}$ is off and $a_{i}=1$ if $a_{i}$ is on for $i=1,2, \ldots, n$ for domain space. Similarly, $B=\left(b_{1}, \ldots, b_{m}\right), b_{j} \in\{0,1\}$ where $j=$ $1,2, \ldots, m . B$ is the instantaneous state vector of the range space. $b_{j}=0$ if $b_{j}$ is off and $b_{j}=1$ if $b_{j}$ is on for $j=1,2, \ldots, m$ for range space.

- Let $D_{i} R_{j}$ (or $R_{j} D_{i}$ ) be the edges of an FRM where $j=1,2, \ldots, m$ and $i=1,2, \ldots, n$ form a directed cycle, FRM is said to be cycle if it possesses a directed cycle. Otherwise, it is acyclic.

- An FRM with cycle is said to be an FRM with feedback. When there is feedback in the FRM, the FRM is called a dynamical system.

- Let $D_{i} R_{j}$ (or $R_{j} D_{i}$ )where $1 \leq j \leq m$ and $1 \leq i \leq n$. When $D_{i}$ (or $R_{j}$ ) is switched on and if causality flows and if again causes $D_{i}$ (or $R_{j}$ ) an equilibrium is attained. This equilibrium state is called hidden pattern.

- If the equilibrium state of this system is a unique state vector then it is called fixed point.

Example: Let us assume dynamical system by switching on $R_{1}$ (or $D_{1}$ ). FRM settles down with $R_{1}$ and $R_{m}\left(D_{1}\right.$ and $\left.D_{n}\right)$ on i.e. state vector remains as $(1,0, \ldots 0,1)$ as in $R(1,0, \ldots, 0,1)$. This state vector is called the fixed point.

- If the FRM reach a state vector in the forms: $D_{1} \rightarrow$ $D_{2} \rightarrow \ldots \rightarrow D_{i} \rightarrow D_{1}\left(R_{1} \rightarrow R_{2} \rightarrow \ldots \rightarrow R_{i} \rightarrow\right.$ $R_{1}$ ); This form is called limit cycle.

- Let $E_{1}, E_{2}, \ldots \ldots, E_{p}$ be the relational matrices of the FRMs. Combined FRMs denotes the relational matrix by $E=E_{1}+E_{2}+\cdots+E_{p}$.

- Let $R_{1}, R_{2}, \ldots, R_{m}$ and $D_{1}, D_{2}, \ldots, D_{n}$ be the nodes of FRM. Let us assume $D_{1}$ is switched on i.e. when an input is given as vector $A_{1}=(1,0, \ldots, 0)$ in $D_{1}$ and the relational matrix is $E$. Now $A_{1} E=\left(r_{1}, r_{2}, \ldots, r_{m}\right)$, after thresholding and updating the resultant vector $A_{1} E \in R$. Now let $B=A_{1} E$, passing $B$ into $E^{T}$ and obtain $B E^{T}$. After threshold and update the vector 
$B E^{T} \in D$. The procedure repeated till we get a fixed point or limit cycle.

\section{FUZZY MODEL}

In this section we describe the basic notions of Fuzzy Bimodel.

\section{A. Bi-Set}

Let $B M=B M_{1} \cup B M_{2}$, where $B M_{1}$ and $B M_{2}$ are nonempty sets with $B M_{1} \nsubseteq B M_{2}$ and $B M_{2} \nsubseteq B M_{1}$, then we call $B M$ as biset.

\section{B. Bi-Vector}

Let $X_{1}=\left(x_{1}, x_{2}, \ldots, x_{n}\right)$ and $X_{2}=\left(x^{\prime}{ }_{1}, x^{\prime}{ }_{2}, \ldots, x_{m}^{\prime}\right)$ be the two vectors of length $\mathrm{n}$ and $\mathrm{m}$ respectively. Then $X=$ $X_{1} \cup X_{2}$ is a bi-vector. Let $X=X_{1} \cup X_{2}=(2104) \cup(4125)$, where $X$ is a bi-vector. Now, $X=X_{1} \cup X_{2}=(000) \cup(000)$, where $A$ is a zero vector. If $X=X_{1} \cup X_{2}=(1111) \cup(1111)$, then $X$ is an unit vector.

\section{Bi-matrix}

A matrix $B M T$ is said to be a fuzzy bi-matrix if $B M T=$ $B M T_{1} \cup B M T_{2}$ where $B M T_{1}$ and $B M T_{2}$ are two different matrices. Example: let $B M T=B M T_{1} \cup B M T_{2}=(0101) \cup$ (1100), then $B M T$ is called a bi-matrix or row bi- matrix. Let $B M T=B M T_{1} \cup B M T_{2}=\left[\begin{array}{ll}1 & 9 \\ 2 & 0\end{array}\right] \cup\left[\begin{array}{ll}1 & 6 \\ 8 & 5\end{array}\right]$ then $B M T$ is called square bi-matrix.

\section{Bi-graph}

Let $B G=B G_{1} \cup B G_{2}$ where $B G_{1}$ and $B G_{2}$ are two distinct graphs then we call $G$ as a bi-graph.

\section{E. Product rule of bi-matrix}

Let $B M T=B M T_{1} \cup B M T_{2}$ be a bi-matrix where $B M T_{1}$ is a $m \times n$ matrix and $B M T_{2}$ is a $p \times s$ matrix. If $X=X_{1} \cup X_{2}$ is a bi-vector such that $X_{1}$ has $m$ components and $X_{2}$ has $p$ components then the product of $X$ with $A$ is defined as $X B M T=\left(X_{1} \cup X_{2}\right)\left(B M T_{1} \cup B M T_{2}\right)=X_{1} B M T_{1} \cup X_{2} B M T_{2}$. is a $1 \times s$ matrix or more mathematically; $X_{1} B M T_{1} \cup$ $X_{2} B M T_{2}=Y_{1} \cup Y_{2}$ a bi-vector or a row bi-vector.

\section{F. Bi-transpose of bi-matrix}

Let $B M=B M_{1} \cup B M_{2}$ be a bi-matrix. Then the bitranspose of the bi-matrix $B M$ is defined as $B M^{t}=$ $\left(B M_{1} \cup B M_{2}\right)^{t}=B M_{1}^{t} \cup B M_{2}^{t}$.

\section{FuZZY COGNITIVE RELATIONAL MAPS}

Fuzzy Cognitive Relational Maps (FCRMs) is a directed bigraph where the pair of associated nodes are bi-nodes. If the order of the bi-matrix associated with FCRMs is $n \times n$ square matrix and $p \times m$ matrix then the bi-nodes are bi- vectors of length $(n, p)$ or length $(n, m)$.

\section{A. Adjacency Bi-matrix}

Consider the bi-nodes concepts $\left\{C^{1}{ }_{1}, C^{1}{ }_{2}, \ldots, C^{1}{ }_{n}\right\}$ of FCMs and $\left\{D_{1}, \ldots, D_{p}\right\}$ and $\left\{R_{1}, \ldots, R_{m}\right\}$ of FRMs to define a new FCRMs model. Suppose the directed graph is drawn using the edge bi-weight $e^{t}{ }_{i j}=\{0,1,-1\}, 1 \leq t \leq 2$. The bi-matrix $B M=B M_{1} \cup B M_{2}$ is defined by $e^{1}{ }_{i j} \cup e^{2}{ }_{k s}$, where $e^{1}{ }_{i j}$ is the weight of the directed edge $C_{i} C_{j}$ and $e^{2}{ }_{k s}$ is the directed edge of $D_{k} R_{s} . B M$ is called adjacency bi-matrix of FCRMs model, also known as the connecting relational bi-matrix of FCRMs model.

\section{B. Instantaneous rate}

Let $\left\{C_{1}, \ldots, C_{n}\right\} \cup\left\{\left(D_{1}, \ldots, D_{p}\right) \cup\left(R_{1}, \ldots, R_{m}\right)\right\}$ be the binodes of FCRMs. Now $A=A_{1} \cup A_{2}=\left(a_{1}, a_{2}, \ldots, a_{n}\right) \cup$ $\left(b_{1}, b_{2}, \ldots, b_{p}\right)\left(\operatorname{or}\left(c_{1}, c_{2}, \ldots, c_{m}\right)\right) \quad$ where $a_{i}, b_{j}, c_{t} \in\{0,1\}$ $1 \leq i \leq n, 1 \leq j \leq p$ and $1 \leq t \leq$. A is called instantaneous state bi-vector and it denotes the $O N-O F F$ position of the node at an instant.

1) $a_{j}=0$ if $a_{j}$ is OFF and $a_{j}=1$ if $a_{j}$ is $O N$ for $1 \leq j \leq$ $n$.

2) $b_{i}=0$ if $b_{i}$ is OFF and $b_{i}=1$ if $b_{i}$ is ON for $1 \leq i \leq$ $p$.

3) $c_{t}=0$ if $b_{i}$ is OFF and $c_{t}=1$ if $c_{t}$ is ON for $1 \leq t \leq$ $m$

\section{Bi-cyclic FCRMs}

Let $\left\{C_{1}, \ldots, C_{n}\right\} \cup\left\{\left(D_{1}, \ldots, D_{p}\right) \cup\left(R_{1}, \ldots, R_{m}\right)\right\}$ be the binodes of FCRMs. Now $C_{i} C_{j} \cup D_{s} R_{k}$ be the bi-edges of FCRMs where $i \neq j, 1 \leq i, j \leq n, 1 \leq s \leq p$ and $1 \leq k \leq m$, then the bi-edges form a directed bi-cycle. An FCRMs are said to be bicyclic if it possesses a directed bi-cycle. FCRMs are said to be abi-cyclic if it does not possess any directed bi-cycle.

\section{Dynamicalbi-system}

An FCRMs with bi-cycles is said to have a feedback, when there is a feedback in an FCRMs, i.e. when the causal relations flow through a cycle in a revolutionary way, the FCRMs are called a dynamical bi-systems.

\section{E. Hidden bi-pattern}

Let $\left\{C_{1} C_{2}, C_{2} C_{3}, \ldots, C_{n-1} C_{n}\right\} \cup\left\{\left(D_{i} R_{j}\right) \operatorname{or}\left(R_{j} D_{i}\right) \mid 1 \leq i \leq\right.$ $p, 1 \leq j \leq m\}$ be a bi-cycle. If $C_{i} \cup R_{j}\left(\right.$ or $\left.D_{j}\right)$ is switched ON and if the causality flows through the edges of the bi-cycle and if it again causes $C_{i} \cup R_{j}\left(\right.$ or $\left.D_{j}\right)$ we say that the dynamical bisystem in a loop. This is true for the bi-nodes $C_{i} \cup$ $R_{j}\left(\right.$ or $\left.D_{j}\right)$ for $1 \leq i \leq n, 1 \leq j \leq m($ or $1 \leq j \leq p) \quad$ The equilibrium bi-state for the dynamical bi-system is called hidden pattern. If the equilibrium bi-state of the dynamical bisystem is a unique bi-state bi-vector then it is called fixed bipoint.

\section{F. Limit-bicycle}

If the FCRMs settles down with a bi-state bi-vector repeating in the form $A_{1} \rightarrow A_{2} \rightarrow \cdots \rightarrow A_{1} \cup B_{1} \rightarrow B_{2} \rightarrow \cdots \rightarrow$ $B_{1}\left(\left(\right.\right.$ or $\left.D_{1} \rightarrow D_{2} \rightarrow \cdots D_{1}\right)$ then this equilibrium is called a limit bi-cycle.

\section{G. Threshold and update}

Suppose $A=A_{1} \cup A_{2}$ is bi-vector which is passes into a dynamical bi-system $E=E_{1} \cup E_{2}$. Then $A E=A_{1} E_{1} \cup A_{2} E_{2}=$ $\left(x^{\prime}{ }_{1}, x^{\prime}{ }_{2}, \ldots, x^{\prime}{ }_{n}\right) \cup\left(y^{\prime}{ }_{1}, y^{\prime}{ }_{2}, \ldots, y_{p}^{\prime}\right)\left(\operatorname{or}\left(\left(z^{\prime}{ }_{1}, z^{\prime}{ }_{2}, \ldots, z^{\prime}{ }_{m}\right)\right)\right.$ after thresholding and updating the bi-vector; suppose we get 
$\left(x_{1}, x_{2}, \ldots, x_{n}\right) \cup\left(y_{1}, \ldots, y_{p}\right)\left(\operatorname{or}\left(z_{1}, \ldots, z_{m}\right)\right)$ we denote that by $\left(x_{1}^{\prime}, x^{\prime}{ }_{2}, \ldots, x_{n}^{\prime}\right) \cup\left(y_{1}^{\prime}, y_{2}^{\prime}, \ldots, y_{p}^{\prime}\right)$

$\operatorname{or}\left(\left(z^{\prime}{ }_{1}, z^{\prime}{ }_{2}, \ldots, z^{\prime}{ }_{m}\right) \Leftrightarrow\left(x_{1}, x_{2}, \ldots, x_{n}\right) \cup\right.$ $\left(y_{1}, \ldots, y_{p}\right)\left(\operatorname{or}\left(z_{1}, \ldots, z_{m}\right)\right)$. Thus the symbol $\Leftrightarrow$ means the resultant bi-vector has been threshold and updated.

\section{H. Properties of bi-edges}

The bi-edges $e_{i j}=\left(e^{1}{ }_{i j}\right) \cup\left(e^{2}{ }_{k s}\right)$ take the values in fuzzy causal bi-interval $[-1,1] \cup[-1,1]$. We have 9 possibilities in FCRMs which making the solution of the problem more sensitive or accurate.

1) $e_{i j}=0$ denotes no causality between the bi-nodes.

2) $e_{i j}>0$ indicates that both $e^{1}{ }_{i j}>0$ and $e^{2}{ }_{k s}>0$; this implies increase in bi-nodes $C_{i} \cup D_{k}\left(\right.$ or $\left.R_{s}\right)$.

3) $e_{i j}<0$ indicates that both $e^{1}{ }_{i j}<0$ and $e^{2}{ }_{k s}<0$; this implies decrease in bi-nodes $C_{i} \cup D_{k}\left(\right.$ or $\left.R_{s}\right)$.

4) Considering the case when $\left(e^{1}{ }_{i j}\right)=0$ and $\left(e^{2}{ }_{k s}\right)>0$ then no relation in one bi-node and an increase in other node.

5) If $\left(e^{1}{ }_{i j}\right)=0$ and $\left(e^{2}{ }_{k s}\right)<0$ then no causality in the FCMs node and decreasing relation in FRMs mode.

6) $\left(e^{1}{ }_{i j}\right)>0$ and $\left(e^{2}{ }_{k s}\right)=0$ then increasing relation in FCMs mode and no relation in FRMs.

7) $\left(e^{1}{ }_{i j}\right)<0$ and $\left(e^{2}{ }_{k s}\right)=0$ then no relation in FRMs and an increasing relation in FCMs mode.

8) $\left(e^{1}{ }_{i j}\right)<0$ and $\left(e^{2}{ }_{k s}\right)>0$ then decreasing relation in FCMs mode and increasing relations in FRMs.

9) $\left(e^{1}{ }_{i j}\right)>0$ and $\left(e^{2}{ }_{k s}\right)<0$ then increasing relation in FCMs mode and decreasing relations in FRMs.

\section{Modification of given problem}

Connection bi-matrix of FCRMs bi-model which has both FCMs and FRMs bi-model. We have assumed $I_{1}$ be the initial input bi-vector. In $I_{1}$, a particular vector components, $c_{1}$ and $d_{1}$, which is in FCMs and FRMs be kept ON state and all other components are OFF state. Now we pass the state vector $I_{1}$ through the FCRMs bi-model. To convert the resultant vector, the values in FCMs and FRMs component which are greater than or equal to one are made as on state and all others denote as OFF state by assigning the values 1 and 0 . The component of FCMs of the resulting vector is kept as it is and the components of FRMs of the resulting vector is multiplied with the inverse of the FCMRs bi-matrix and thresholding yield in a new vector $I_{2}$. Using this new input bi-vector, we repeat the same procedure until a fixed point or a limit cycle is obtained. The process has been repeated for all the vectors separately. From this operation we have found the hidden pattern of some vectors in all or many cases from which we have analyzed the causes.

\section{ANALYZE THE PROBLEMS OF EMPLOYEE EMPLOYER RELATIONSHIP USING FCRMS MODEL}

The most important part of any business is its people. No business can run effectively without them. But people don't work in a vacuum; they need to communicate and work with others to get their jobs done. To be successful, employers need to manage relationships in the workplace to keep the business functioning smoothly, avoid problems and make sure individual employees are performing at their best. An organisation with good employee-employer relations provide fair and consistent treatment to all means employers must provide. Employee relations programs are typically part of a human resource strategy designed to ensure the most effective use of people to accomplish the organization's mission. Human resource strategies are deliberate plans companies use to help them gain and maintain a competitive edge in the marketplace. One way to stay ahead is to make sure employees are happy so they don't leave their job and go work for the competition. An effective employee-employer relations program starts with clearly written policies which describe the company's rules, philosophy, procedure for addressing employee-related matters and resolving problems in the workplace. Strategies for good employee-employee relations can take many forms and vary by a number of factors including company size, job security, salaries, promotion, responsibility and many more. Now we proceed onto study and analyze the relationship between employee-employer which is the key to the ultimate success of an organization using FCRMs model. According to experts view and adaptation of the necessary requirement of employee and employer in an industry associated to FCMs of FCRMs model have done by taking as the attribute $X_{1}, X_{2}, \ldots, X_{16}$, This is very important, that we have several nodes and several opinions to draw various model of this relationship. Attributes relating with FCMs of FCRMS model are as follows:

$\mathrm{X}_{1} \rightarrow \quad$ Pay with allowances and bonus to the employee

$\mathrm{X}_{2} \rightarrow \quad$ Only pay to the employee

$\mathrm{X}_{3} \rightarrow \quad$ Pay with allowances (or bonus) to the

employee

\begin{tabular}{|c|c|}
\hline $\mathrm{X}_{4} \rightarrow$ & Best performance \\
\hline $\mathrm{X}_{5} \rightarrow$ & Average performance \\
\hline $\mathrm{X}_{6} \rightarrow$ & Poor performance \\
\hline $\mathrm{X}_{7} \rightarrow$ & Employee works more number of hours \\
\hline $\mathrm{X}_{8} \rightarrow$ & Employee works less number of hours \\
\hline $\mathrm{X}_{9} \rightarrow$ & Maximum profit to the industry \\
\hline $\mathrm{X}_{10} \rightarrow$ & Only profit to the industry \\
\hline $\mathrm{X}_{11} \rightarrow$ & Neither profit nor loss to the industry \\
\hline $\mathrm{X}_{12} \rightarrow$ & Loss to the industry \\
\hline $\mathrm{X}_{13} \rightarrow \mathrm{H}$ & Heavy loss to the industry \\
\hline $\mathrm{X}_{14} \rightarrow$ & Stop work or strike by the employee \\
\hline $\begin{array}{l}X_{15} \rightarrow \\
\text { employer }\end{array}$ & Good relation between employee \\
\hline
\end{tabular}

$\mathrm{X}_{16} \rightarrow \quad$ Demand of the employee which are not fulfilled

Similarly we have drawn aFRMs of the bi-matrix FCRMs model. We have taken 16 nodes $D_{1}, D_{2}, \ldots, D_{16}$, in domain space which denote the employee's requirement. 
$D_{1} \rightarrow$ Salaries ways \& other benefit

$D_{2} \rightarrow$ Company policies \& administration

$D_{3} \rightarrow$ Good inter personal relationship

$D_{4} \rightarrow$ Quality supervisor

$D_{5} \rightarrow$ Job security

$D_{6} \rightarrow$ Working condition

$D_{7} \rightarrow$ Work/life balance

$D_{8} \rightarrow$ Sense of personal achievement

$D_{9} \rightarrow$ Status

$D_{10} \rightarrow$ Recognition

$D_{11} \rightarrow$ Challenging/ stimulating work

$D_{12} \rightarrow$ Responsivility

$D_{13} \rightarrow$ Opportunity for advancement

$D_{14} \rightarrow$ Promotion

$D_{15} \rightarrow$ Growth

$D_{16} \rightarrow$ Feedback \& support

The attributes $R_{1}, R_{2}, R_{3}, R_{4}, R_{5}, R_{6}, R_{7}, R_{8}$ that is relate to owner of any industry have briefly described.

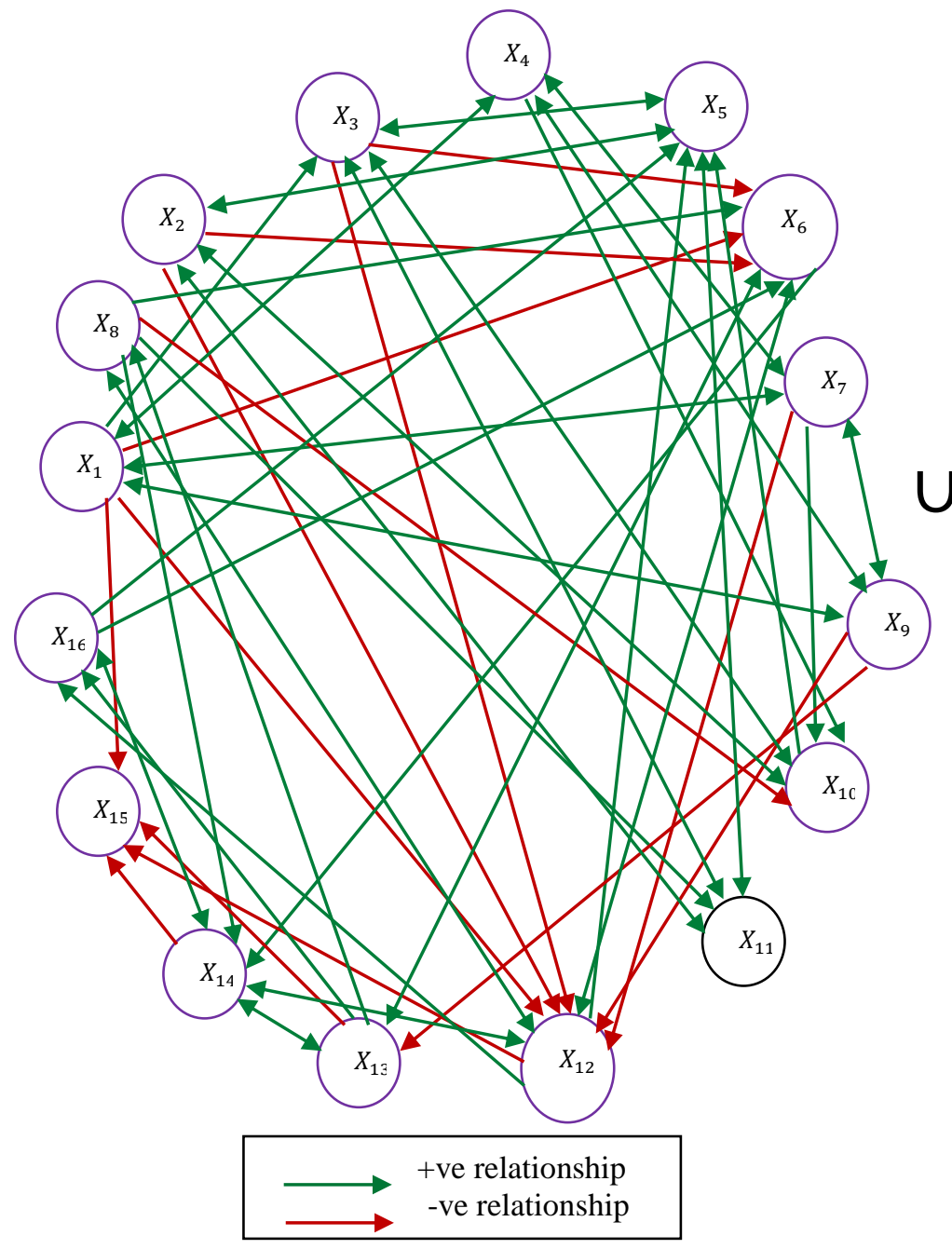

Fig. 1. Employee -employer relationship model representation by a FCRMs Bi-Mode
$R_{1} \rightarrow \quad$ Offer clearly defined and specialized employment opportunities

$R_{2} \rightarrow \quad$ Reinforce the need to follow organization policies and practice

$R_{3} \rightarrow \quad$ Linked rewards and benefits to fulfilling, job requirement

$R_{4} \rightarrow \quad$ Structure work condition

$R_{5} \rightarrow \quad$ Reward employee who are loyal to the organization

$R_{6} \rightarrow \quad$ Provide opportunities for employee to develop technical skill

$$
\begin{array}{ll}
R_{7} \rightarrow & \text { Achievement of the industry } \\
R_{8} \rightarrow & \text { Good manager relationship }
\end{array}
$$

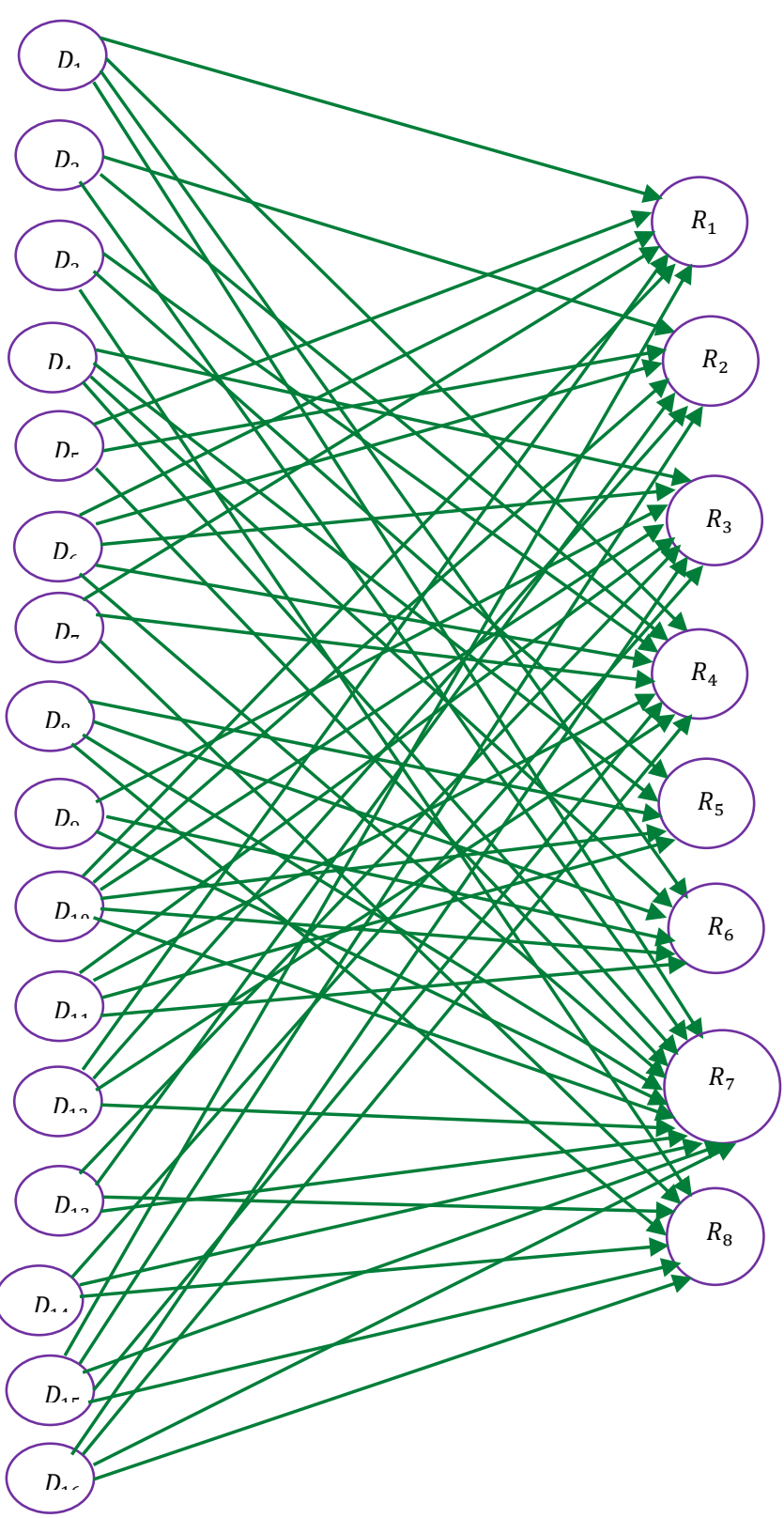


With the help of relational model we have drawn a adjacency matrix called E.

TABLE I. ADJACENCY MATRIX OF FCRMS

\begin{tabular}{|c|c|c|c|c|c|c|c|c|c|c|c|c|c|c|c|c|}
\hline & $\mathrm{X}_{1}$ & $\mathrm{X}_{2}$ & $\mathrm{X}_{3}$ & $\mathrm{X}_{4}$ & $\mathrm{X}_{5}$ & $\mathrm{X}_{6}$ & $\mathrm{X}_{7}$ & $\mathrm{X}_{8}$ & $\overline{X_{9}}$ & $\mathrm{X}_{10}$ & $\mathrm{X}_{11}$ & $\mathrm{X}_{12}$ & $\mathrm{X}_{13}$ & $\mathrm{X}_{14}$ & $\mathrm{X}_{15}$ & $\mathrm{X}_{16}$ \\
\hline $\mathrm{X}_{1}$ & 0 & 0 & 1 & 1 & 0 & -1 & 1 & 0 & 1 & 0 & 0 & -1 & 0 & 0 & 1 & 0 \\
\hline $\mathrm{X}_{2}$ & 0 & 0 & 0 & 0 & 1 & -1 & 0 & 0 & 0 & 1 & 1 & -1 & 0 & 0 & 0 & 0 \\
\hline $\mathrm{X}_{3}$ & 0 & 0 & 0 & 0 & 1 & -1 & 0 & 0 & 0 & 1 & 1 & -1 & 0 & 0 & 0 & 0 \\
\hline $\mathrm{X}_{4}$ & 1 & 0 & 0 & 0 & 0 & 0 & 1 & 0 & 1 & 1 & 0 & 0 & 0 & 0 & 0 & 0 \\
\hline$X_{5}$ & 0 & 1 & 1 & 0 & 0 & 0 & 0 & 0 & 0 & 0 & 1 & 0 & 0 & 0 & 0 & 0 \\
\hline $\mathrm{X}_{6}$ & 0 & 0 & 0 & 0 & 0 & 0 & 0 & 0 & 0 & 0 & 0 & 1 & 1 & 1 & 0 & 0 \\
\hline$X_{7}$ & 1 & 0 & 0 & 1 & 0 & 0 & 0 & 0 & 1 & 1 & 0 & -1 & 0 & 0 & 0 & 0 \\
\hline $\mathrm{X}_{8}$ & 0 & 0 & 0 & 0 & 0 & 1 & 0 & 0 & 0 & -1 & 1 & 1 & 0 & 1 & 0 & 0 \\
\hline$X_{9}$ & 1 & 0 & 0 & 1 & 0 & 0 & 1 & 0 & 0 & 0 & 0 & -1 & -1 & 0 & 0 & 0 \\
\hline $\mathrm{X}_{10}$ & 0 & 1 & 1 & 0 & 1 & 0 & 0 & 0 & 0 & 0 & 0 & 0 & 0 & 0 & 0 & 0 \\
\hline$X_{11}$ & 0 & 1 & 1 & 0 & 1 & 0 & 0 & 0 & 0 & 0 & 0 & 0 & 0 & 0 & 0 & 0 \\
\hline $\mathrm{X}_{12}$ & 0 & 0 & 0 & 0 & 1 & 1 & 0 & 1 & 0 & 0 & 0 & 0 & 0 & 1 & -1 & 1 \\
\hline $\mathrm{X}_{13}$ & 0 & 0 & 0 & 0 & 0 & 1 & 0 & 1 & 0 & 0 & 0 & 0 & 0 & 1 & -1 & 1 \\
\hline $\mathrm{X}_{14}$ & 0 & 0 & 0 & 0 & 0 & 0 & 0 & 0 & 0 & 0 & 0 & 1 & 1 & 0 & -1 & 1 \\
\hline$X_{15}$ & 0 & 0 & 0 & 0 & 0 & 0 & 0 & 0 & 0 & 0 & 0 & 0 & 0 & 0 & 0 & 0 \\
\hline $\mathrm{X}_{16}$ & 0 & 0 & 0 & 0 & 1 & 1 & 0 & 0 & 0 & 0 & 0 & 0 & 0 & 1 & 0 & 0 \\
\hline
\end{tabular}

$\mathrm{E}=$

\begin{tabular}{|c|cccccccc|}
\cline { 2 - 8 } \multicolumn{1}{c}{} & $\mathrm{R}_{1}$ & $\mathrm{R}_{2}$ & $\mathrm{R}_{3}$ & $\mathrm{R}_{4}$ & $\mathrm{R}_{5}$ & $\mathrm{R}_{6}$ & $\mathrm{R}_{7}$ & $\mathrm{R}_{8}$ \\
\hline $\mathrm{D}_{1}$ & 1 & 0 & 0 & 1 & 0 & 1 & 1 & 0 \\
$\mathrm{D}_{2}$ & 0 & 1 & 0 & 1 & 0 & 0 & 1 & 0 \\
$\mathrm{D}_{3}$ & 0 & 0 & 0 & 1 & 1 & 0 & 0 & 1 \\
$\mathrm{D}_{4}$ & 0 & 0 & 1 & 0 & 1 & 1 & 1 & 0 \\
$\mathrm{D}_{5}$ & 1 & 1 & 0 & 0 & 0 & 0 & 1 & 0 \\
$\mathrm{D}_{6}$ & 1 & 1 & 1 & 1 & 0 & 0 & 1 & 1 \\
$\mathrm{D}_{7}$ & 1 & 0 & 0 & 1 & 0 & 0 & 0 & 0 \\
$\mathrm{D}_{8}$ & 0 & 0 & 0 & 0 & 1 & 1 & 1 & 0 \\
$\mathrm{D}_{9}$ & 0 & 0 & 1 & 0 & 0 & 1 & 1 & 0 \\
$\mathrm{D}_{10}$ & 1 & 1 & 1 & 0 & 1 & 1 & 1 & 0 \\
$\mathrm{D}_{11}$ & 0 & 0 & 1 & 1 & 1 & 1 & 0 & 1 \\
$\mathrm{D}_{12}$ & 1 & 1 & 0 & 1 & 0 & 0 & 1 & 1 \\
$\mathrm{D}_{13}$ & 0 & 1 & 1 & 0 & 0 & 0 & 1 & 1 \\
$\mathrm{D}_{14}$ & 0 & 0 & 1 & 0 & 0 & 0 & 1 & 1 \\
$\mathrm{D}_{15}$ & 1 & 1 & 0 & 1 & 0 & 0 & 1 & 1 \\
$\mathrm{D}_{16}$ & 0 & 0 & 1 & 1 & 0 & 0 & 1 & 1 \\
\hline
\end{tabular}

Here E denotes the connection matrix of the directed graph of FCRMs model. Considering all cases on this relationship model with taking some nodes are on or off and try to find out some hidden pattern

Case 1:

Now we have considered the node $X_{1}$ (Pay with allowances and bonus to the employee) in FCMs and $D_{1}$ (Salaries and other benefits) in FRMs as the on state and all the remaining nodes are in the $O F F$ state.

According the FCRMs method when the same threshold value occurs twice, the value is considered as the fixed point and the iteration and also the calculation gets terminated. Similarly we consider all the different input vectors on and find the hidden patterns for this FCRMs model which are shown in table 
TABLE II. THE SET OF FIXED POINTS CORRESPONDS TO DIFFERENT INPUT VECTORS OF FCRMS

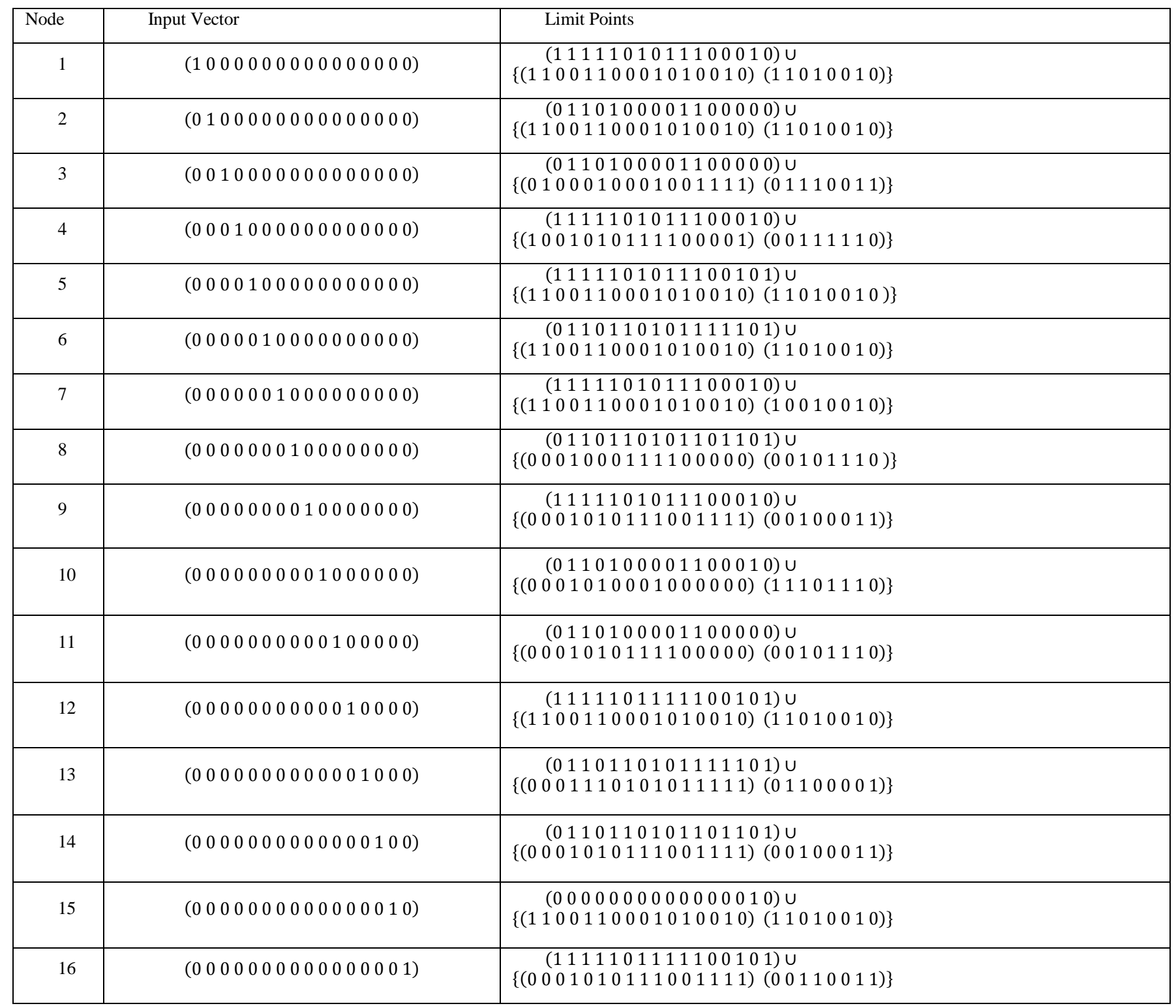

Hence from the above table 2 we define the set of limit points as well as fixed point for each different input vectors of FCRMs bi-model and observe the hidden pattern of each cases. Hidden pattern of some vectors found in all or many cases. Inference from this hidden pattern summarizes or highlights the causes.

\section{INDUCED FuZZY COGNITIVE RELATIONAL MAPS}

Induced Fuzzy Cognitive Relational Maps (IFCRMs) is a modified version of FCRMs. IFCRMs focussed on algorithmic approaches of FCRMs which works on unsupervised data to derive an optimistic solution.

Step 1: Collect the nodes for the given problem, which is unsupervised data that is in determinant factors.

Step 2: Draw the directed bi-graph for FCRMs model, according to the expert opinion.
Step 3: From FCRMs, obtain the connection matrix $\mathrm{E}$ which is combination of both FCMs and FRMs.

Step 4: $\quad$ Consider the initial input bi-vector $C_{1}$ by setting the first component of this vector $C_{1}$ in ON position which is denoted by 1 and the rest of the components as 0 which are OFF state.

Step 5: $\quad$ Find $M=C_{1} \times E$. At each stage the state vector is updated and threshold. The symbol ' ' represents the threshold value for the product of the result. The threshold value is calculated from $\mathrm{M}$ of FCMs components by assigning 1 for the values $x_{1}>0$ and assigning 0 when $x_{1}<0$ and two highest values in FRMs components are assigned as $O N$ state and all others as $O F F$ state by the giving values 1 or 0 .

Step 6: The new bi-vector is related with the bimatrix and that bi-vector which triggers the highest number 
of attributes to $O N$ state i.e. for each positive entry we get a set of resultant vectors from which a vector which contain maximum number of $1 \mathrm{~s}$ is chosen as $C_{2}$. If there are two or more bi-vector with equal number of $1 \mathrm{~s}$ as $O N$ state, choose the first occurring one.

Step 7: $\quad$ Considered as fixed point when the same threshold value occurs twice and the iteration gets terminated. This process is done to give due importance to each vector separately as one vector induces another or many more vectors into $O N$ state.

Step 8: $\quad$ Set the state vector $C_{2}$ in $O N$ state which is assigning the second component of the vector to be 1 and the rest of the components as 0 . Precede the calculations discussed in steps 4 to 7 .

Step 9: Continue the above process for all the remaining state vector $C_{n}$ and find out the hidden pattern.

VII. ANALYZE THE RELATIONS BETWEEN EMPLOYEEEMPLOYER USING FCRMS MODEL

We illustrate a general study to access the impact of daily requirement, satisfactory and dissatisfactory problems of both workers and owner of an Industry. We consider the dynamical system of this problem. At the first stage, we have taken the connection matrix $E$ of the directed graph of FCRMs model.

Let

$X_{1}=\left(\begin{array}{llllllllllllllll}1 & 0 & 0 & 0 & 0 & 0 & 0 & 0 & 0 & 0 & 0 & 0 & 0 & 0 & 0 & 0\end{array}\right) \cup$

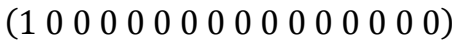

$X_{1} E=\left(\begin{array}{lllllllll}0 & 0 & 1 & 10 & 0 & 1 & 10100-10010 & 0 & 0\end{array}\right.$

$\left(\begin{array}{llllllll}1 & 0 & 0 & 1 & 0 & 1 & 1 & 0\end{array}\right)$

$\Leftrightarrow(1011001010000010) \cup$

$\left(\begin{array}{llllllll}1 & 0 & 0 & 1 & 0 & 1 & 1 & 0\end{array}\right)$

$X^{T}{ }_{1} E=\left(\begin{array}{lllllllllllll}1 & 0 & 1 & 0 & 0 & 0 & 0 & 0 & 0 & 0 & 0 & 0 & 10\end{array}\right) \cup$

(4211232223231132)

(1011001010000010) U

$\left(\begin{array}{lllllllllllll}1 & 0 & 0 & 0 & 0 & 1000 & 0 & 0 & 0 & 010\end{array}\right)=X_{1}{ }^{\prime}$

Let $\quad X_{1}{ }^{\prime}=X C_{1}{ }^{\prime} \cup X R_{1}{ }^{\prime}$

Let $X C_{1}{ }^{\prime}$ is the $O N$ state are $X_{3}, X_{4}, X_{7}, X_{9}, X_{15}$ and in $X R_{1}{ }^{\prime}$ the $O N$ states are $D_{6}, D_{10}, D_{12}, D_{15}$.

Now considering each vector as $O N$.

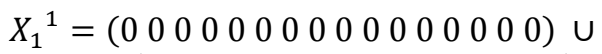

$(10000000000000000)$

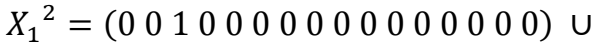

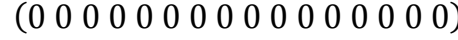

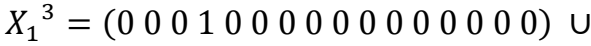

$\left(\begin{array}{llllllllllll}0 & 0000000000000\end{array}\right.$

$X_{1}^{4}=\left(\begin{array}{llllllllllllllll}0 & 0 & 0 & 1 & 0 & 0 & 0 & 0 & 0 & 0 & 0 & 0 & 0 & 0 & 0 & 0\end{array}\right) \cup$

$(0000010000000000)$

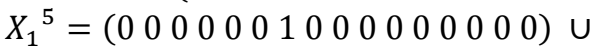

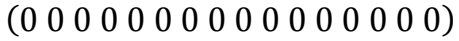

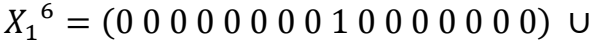

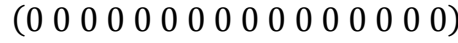

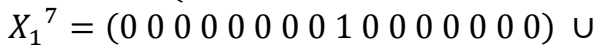

$(0000000001000000)$

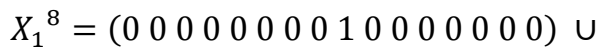

$$
\begin{aligned}
& (0000000000010000)
\end{aligned}
$$

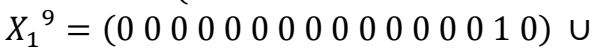

$$
\begin{aligned}
& \left(\begin{array}{lllllllllllll}
0 & 0 & 0 & 0 & 0 & 0 & 0 & 0 & 0 & 0 & 0 & 10
\end{array}\right)
\end{aligned}
$$

Now passing through the bi-matrix $E$ to get the new bivector $X_{2}$.

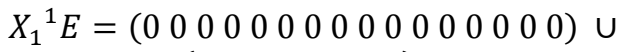

$$
\begin{aligned}
& \text { (1 } 001010110)
\end{aligned}
$$

(100000100101010010)

Row sum: $(0,5)$

$$
\begin{aligned}
& X_{1}{ }^{2} E=\left(\begin{array}{lllllllll}
0 & 0 & 0 & 0 & 1-1000 & 0 & 1 & -10000 & 0
\end{array}\right) \\
& \text { U (0 } 000000000000000000) \\
& \Leftrightarrow(00001000011000000)
\end{aligned}
$$

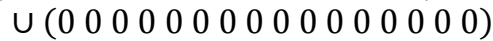

Row sum: $(3,0)$

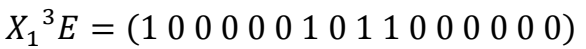

$$
\begin{aligned}
& \text { U (0000000000000000000) }
\end{aligned}
$$

Row sum: $(4,0)$

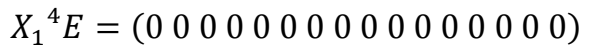

sum: $(0,4)$

$$
\cup(0000110001010010) \quad \text { Row }
$$

$$
\begin{aligned}
& X_{1}{ }^{5} E=\left(\begin{array}{lllllllllllllll}
1 & 0 & 0 & 1 & 0 & 0 & 0 & 0 & 1 & 0 & 0 & 0 & 0 & 0 & 0
\end{array}\right) \\
& \cup\left(\begin{array}{llllllllllllllll}
0 & 0 & 0 & 0 & 0 & 0 & 0 & 0 & 0 & 0 & 0 & 0 & 0 & 0 & 0 & 0
\end{array}\right)
\end{aligned}
$$

Row sum: $(4,0)$

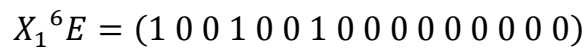

$$
\begin{aligned}
& \cup\left(\begin{array}{llllllllllllllll}
0 & 0 & 0 & 0 & 0 & 0 & 0 & 0 & 0 & 0 & 0 & 0 & 0 & 0 & 0 & 0
\end{array}\right)
\end{aligned}
$$

Row sum: $(3,0)$

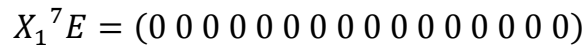

$$
\begin{aligned}
& \cup(00010100001000000)
\end{aligned}
$$

Row sum: $(0,3)$

$$
\begin{aligned}
& X_{1}{ }^{8} E=\left(\begin{array}{lllllllllllllll}
1 & 0 & 0 & 1 & 0 & 0 & 0 & 0 & 1 & 0 & 0 & 0 & 0 & 0 & 0
\end{array}\right) \\
& \cup(1100110001010010)
\end{aligned}
$$

Row sum: $(0,7)$

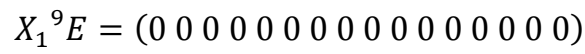

$$
\begin{aligned}
& \cup(1100111001011010)
\end{aligned}
$$

Row sum: $(4,0)$

Now new input vector $X_{2}{ }^{\prime}=X C_{2}{ }^{\prime} \cup X R_{2}{ }^{\prime}$

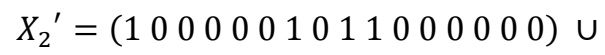

(1100111001011010)

$X_{2}{ }^{1}=\left(\begin{array}{llllllllllllllll}1 & 0 & 0 & 0 & 0 & 0 & 0 & 0 & 0 & 0 & 0 & 0 & 0 & 0 & 0 & 0\end{array}\right) \cup$

$(100000000000000000)$ 


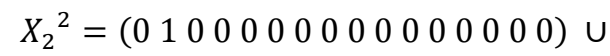

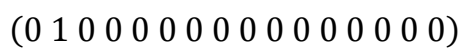

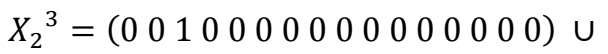

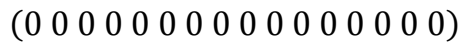

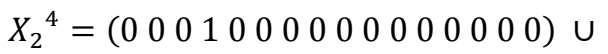

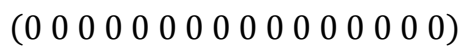

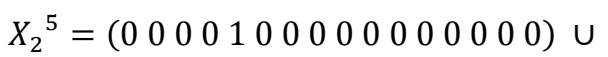

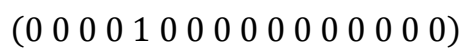

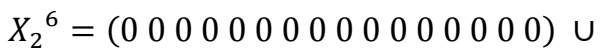

(00000010000000000)

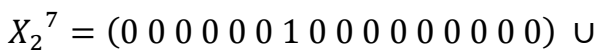

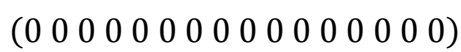

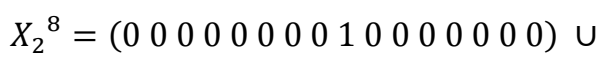

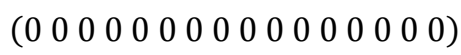

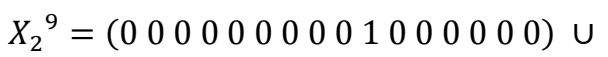

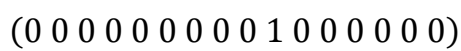

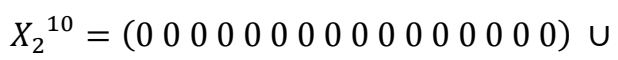

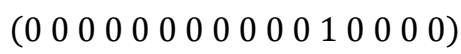

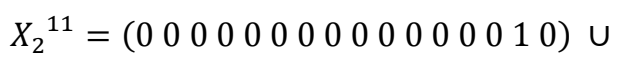

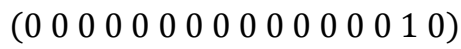

Now passing through the bi-matrix $E$ to get the new bivector $X_{3}$.

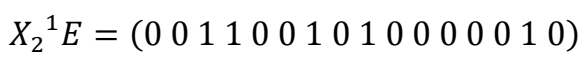

U (1 00000100010010010$)$

Row sum: $(5,5)$

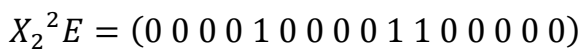

$$
\cup(010000100001010010)
$$

Row sum: $(3,5)$

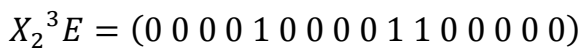

$\cup\left(\begin{array}{lllllllllllllll}0 & 0 & 0 & 0 & 0 & 0 & 0 & 0 & 0 & 0 & 0 & 0 & 0 & 0 & 0\end{array}\right)$

Row sum: $(3,0)$

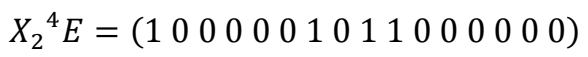

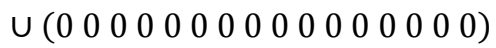

Row sum: $(4,0)$

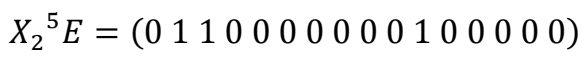

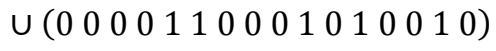

Row sum: $(3,5)$

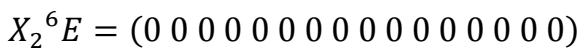

U (0000001100010010010)

Row sum: $(0,4)$

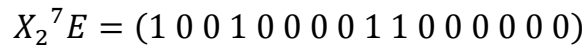

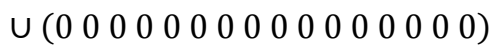

Row sum: $(4,0)$

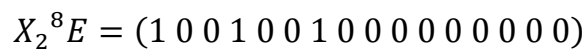

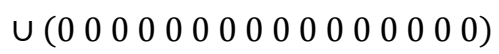

Row sum: $(3,0)$

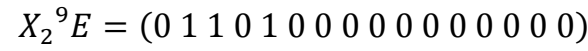

$\cup(0000101000010000000)$

Row sum: $(3,3)$

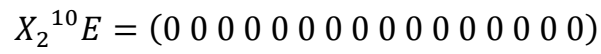

$\cup(1100110001010010)$

Row sum: $(0,7)$

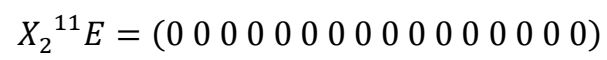

$\cup(1100111001011010)$

Row sum: $(0,9)$

Now new input vector $X_{3}{ }^{\prime}=X C_{3}{ }^{\prime} \cup X R_{2}{ }^{\prime}$

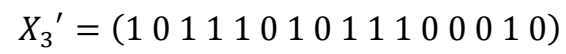
$\cup X R_{2}{ }^{\prime}$

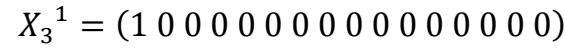
$\cup X R_{2}{ }^{\prime}$

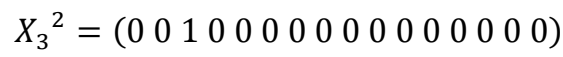
$\cup X R_{2}{ }^{\prime}$

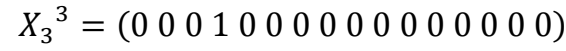
$\cup X R_{2}{ }^{\prime}$

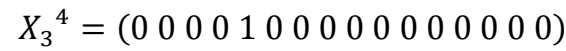
$\cup X R_{2}{ }^{\prime}$

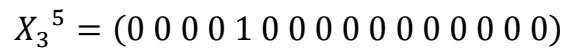
$\cup X R_{2}{ }^{\prime}$

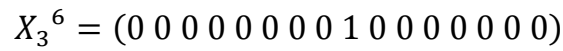
$\cup X R_{2}{ }^{\prime}$

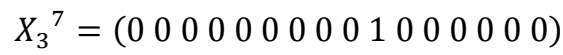
$\cup X R_{2}{ }^{\prime}$

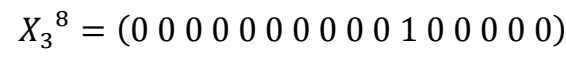
$\cup X R_{2}{ }^{\prime}$

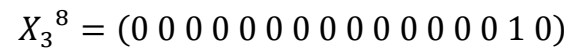
$\cup X R_{2}^{\prime}$ 
Now passing through the bi-matrix $E$ to get the new bivector $X_{4}$.

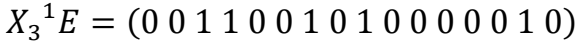

$$
\begin{aligned}
& \cup X R_{2}{ }^{\prime}
\end{aligned}
$$

Row sum: $(0,9)$

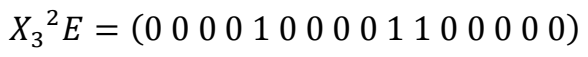

$$
\cup X R_{2}{ }^{\prime}
$$

Row sum: $(3,9)$

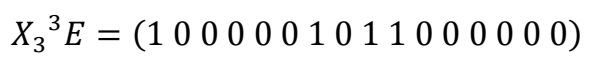

$$
\cup X R_{2}{ }^{\prime}
$$

Row sum: $(4,9)$

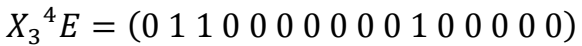

$$
\begin{aligned}
& \cup X R_{2}^{\prime}
\end{aligned}
$$

Row sum: $(3,9)$

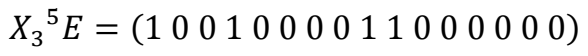

$$
\cup X R_{2}{ }^{\prime}
$$

Row sum: $(4,9)$

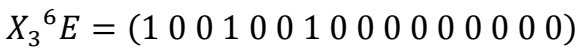

$$
\begin{aligned}
& \cup X R_{2}{ }^{\prime}
\end{aligned}
$$

Row sum: $(3,9)$

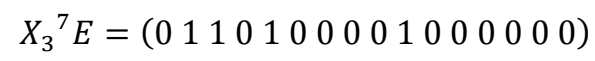

$$
\cup X R_{2}{ }^{\prime}
$$

Row sum: $(4,9)$

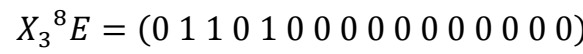

$$
\begin{aligned}
& \cup X R_{2}{ }^{\prime}
\end{aligned}
$$

Row sum: $(3,9)$

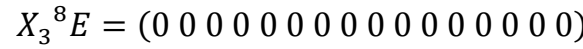

$$
\begin{aligned}
& \cup X R_{2}{ }^{\prime}
\end{aligned}
$$

\begin{tabular}{|c|c|c|c|}
\hline Node & Input Vector & Limit Points & Induced Path \\
\hline 1 & 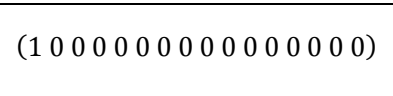 & 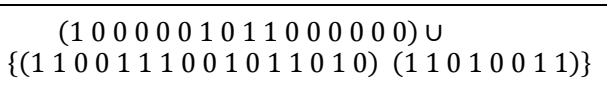 & $\begin{array}{l}\left(C_{1} \rightarrow C_{4} \rightarrow C_{1} \rightarrow C_{4}\right) \cup \\
\left(D_{1} \rightarrow D_{15} \rightarrow D_{15}\right)\end{array}$ \\
\hline 2 & 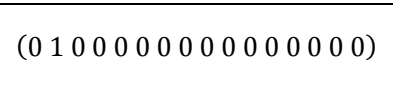 & $\begin{array}{l}(01011010000000000000) \cup \\
\{(110001111000100110010)(11010011)\}\end{array}$ & $\begin{array}{l}\left(C_{2} \rightarrow C_{11} \rightarrow C_{11}\right) \cup \\
\left(D_{2} \rightarrow D_{15} \rightarrow D_{15}\right)\end{array}$ \\
\hline 3 & 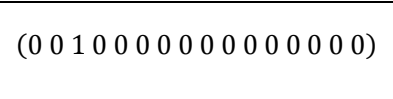 & 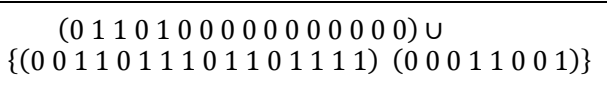 & $\begin{array}{l}\left(C_{3} \rightarrow C_{1} \rightarrow C_{11} \rightarrow C_{4}\right) \cup \\
\left(D_{3} \rightarrow D_{3}\right)\end{array}$ \\
\hline 4 & 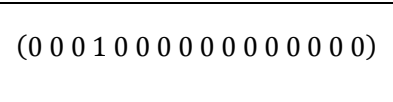 & 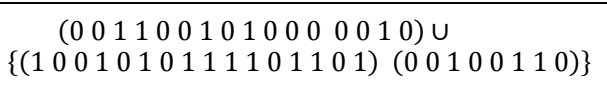 & $\begin{aligned}\left(C_{4} \rightarrow\right. & \left.C_{1} \rightarrow C_{1}\right) \cup \\
& \left(D_{4} \rightarrow D_{9} \rightarrow D_{9}\right)\end{aligned}$ \\
\hline 5 & 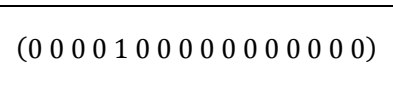 & 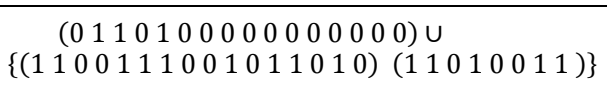 & $\begin{aligned}\left(C_{5} \rightarrow C_{11}\right. & \left.\rightarrow C_{11} \rightarrow C_{4}\right) \cup \\
\left(D_{5}\right. & \left.\rightarrow D_{15} \rightarrow D_{15}\right)\end{aligned}$ \\
\hline 6 & 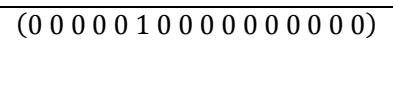 & 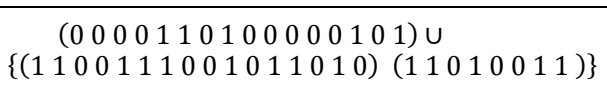 & $\begin{aligned}\left(C_{6} \rightarrow C_{12}\right. & \left.\rightarrow C_{8} \rightarrow C_{12}\right) \cup \\
\left(D_{6}\right. & \left.\rightarrow D_{15} \rightarrow D_{15}\right)\end{aligned}$ \\
\hline 7 & 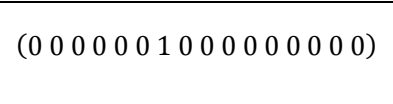 & 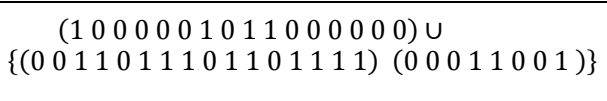 & $\begin{aligned}\left(C_{7} \rightarrow\right. & \left.C_{1} \rightarrow C_{1}\right) \cup \\
& \left(D_{7} \rightarrow D_{3} \rightarrow D_{3}\right)\end{aligned}$ \\
\hline 8 & 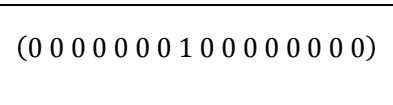 & 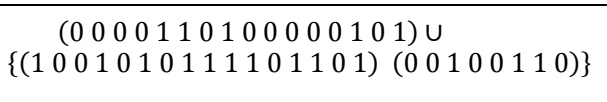 & $\begin{aligned}\left(C_{8} \rightarrow C_{12}\right. & \left.\rightarrow C_{12}\right) \cup \\
\left(D_{8}\right. & \left.\rightarrow D_{9} \rightarrow D_{9}\right)\end{aligned}$ \\
\hline 9 & 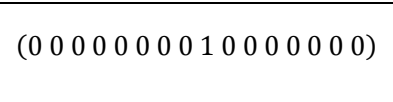 & 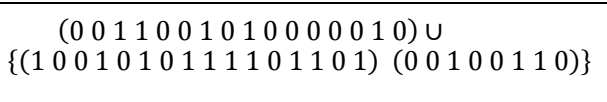 & $\begin{aligned} &\left(C_{9} \rightarrow C_{1} \rightarrow C_{1}\right) \cup \\
&\left(D_{9} \rightarrow D_{9}\right)\end{aligned}$ \\
\hline 10 & 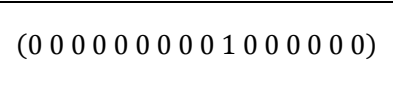 & $\begin{array}{l}\quad(011100000000000000000) \cup \\
\{(10001010011111001101)(00100110)\}\end{array}$ & $\begin{aligned}\left(C_{10} \rightarrow C_{5}\right. & \left.\rightarrow C_{5} \rightarrow C_{4}\right) \cup \\
\left(D_{10}\right. & \left.\rightarrow D_{19} \rightarrow D_{9}\right)\end{aligned}$ \\
\hline
\end{tabular}

Row sum: $(0,9)$

Repeating the above process we get

$$
\begin{aligned}
X_{4}{ }^{\prime}= & (1011101011100010) \\
& \cup(1100111001011010) \\
X_{5}{ }^{\prime}= & (1011101011100010) \\
& \cup(1100111001011010)=X_{4}{ }^{\prime}
\end{aligned}
$$

According the IFCRMs method when the same threshold value occurs twice, the value is considered as the fixed point and the iteration and also the calculation gets terminated. Similarly we consider all the different input vectors on and find the hidden patterns for this IFCRMs model which are shown in table 3 .

TABLE III. INDUCED PATTERN FOR E BY IFCRMS 


\begin{tabular}{|c|c|c|c|}
\hline 11 & 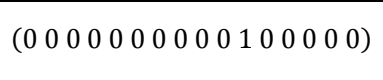 & $\begin{array}{l}(010110000000001000000) \cup \\
\{(10001010011110101101)(00100110)\}\end{array}$ & $\begin{aligned}\left(C_{11} \rightarrow C_{5} \rightarrow C_{5}\right) \cup & \left(D_{11} \rightarrow D_{3}\right. \\
& \left.\rightarrow D_{9}\right)\end{aligned}$ \\
\hline 12 & 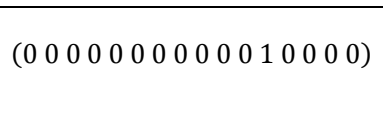 & 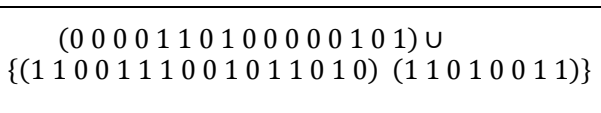 & $\begin{aligned}\left(C_{12} \rightarrow C_{8} \rightarrow C_{12}\right) \cup & \left(D_{12}\right. \\
& \rightarrow D_{15} \\
& \left.\rightarrow D_{15}\right)\end{aligned}$ \\
\hline 13 & 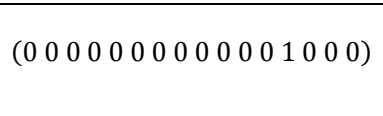 & 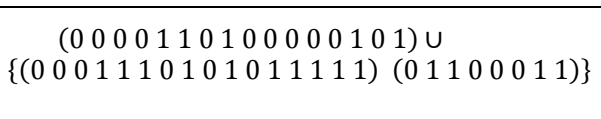 & $\begin{aligned}\left(C_{13} \rightarrow C_{8} \rightarrow C_{12} \rightarrow C_{8}\right) & \\
& \cup\left(D_{13}\right. \\
& \left.\rightarrow D_{13}\right)\end{aligned}$ \\
\hline 14 & 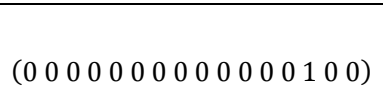 & 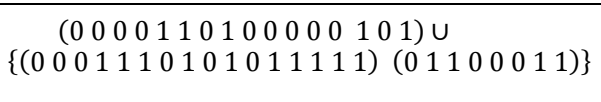 & $\begin{array}{l}\left(C_{14} \rightarrow C_{12} \rightarrow C_{8} \rightarrow C_{12}\right) \cup \\
\left(D_{14} \rightarrow D_{13} \rightarrow D_{13}\right)\end{array}$ \\
\hline 15 & 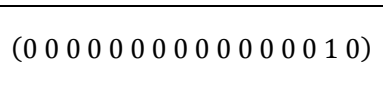 & 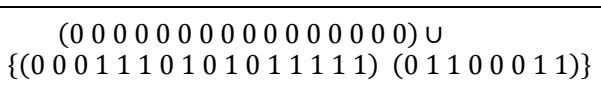 & $\begin{array}{l}\left(C_{15}\right) \cup \\
\left(D_{15} \rightarrow D_{13} \rightarrow D_{13}\right)\end{array}$ \\
\hline 16 & 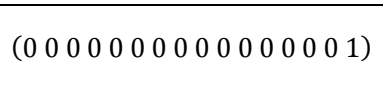 & 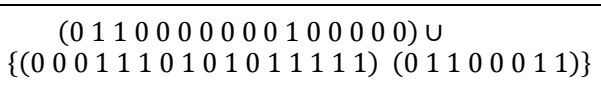 & $\begin{aligned}\left(C_{16} \rightarrow C_{5}\right. & \left.\rightarrow C_{5}\right) \cup \\
\left(D_{16}\right. & \left.\rightarrow D_{13} \rightarrow D_{13}\right)\end{aligned}$ \\
\hline
\end{tabular}

The above table helps us to study the triggering patterns of a particular node which are in $O N$ state when the remaining nodes are in $O F F$ state.
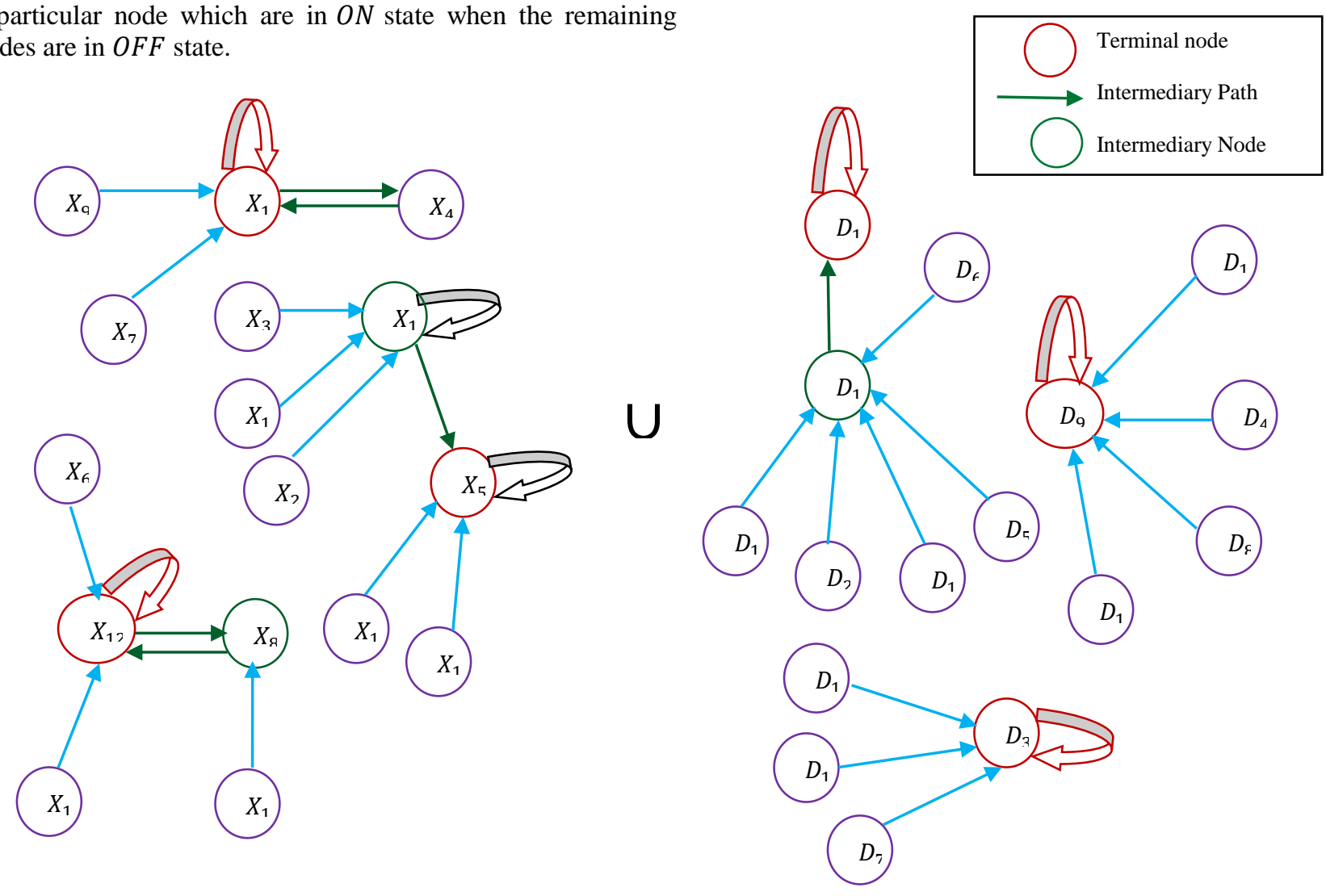

Fig. 2. Induced graph on directed bi-graph 
The interrelationship between the nodes of the above diagram states that $X_{1}$ (pay with allowances and bonus to the employee), $X_{5}$ (average performance) and $X_{12}$ (loss to the industry) is terminal node and $X_{11}$ (neither profit nor loss to the industry), $X_{8}$ (employee works less number of hours) is the intermediary node of this discussed problem. Similarly $D_{13}$ (opportunity for advancement), $D_{9}$ (status of the employee), $D_{3}$ (good inter personal relationship) and $D_{15}$ (growth) are the intermediary nodes.

\section{COMPARISONS BETWEEN FCRMS MODEL AND IFCRMS MODEL}

FCMs have several advantage on various fuzzy model. The main advantage of this method is easy to handle and based on expert's opinion. It also helps to work when the data is unsupervised. This fuzzy model help us to find out the hidden pattern of any type of given problem in any situation. Although this FCMs method are so simple and unique, it has some limitation also. First, this model consists of lengthy procedure for calculation when the matrices has higher number of rows and columns. Second, the manual calculation is fully based on Expert's opinion which may lead the personal bias. According to FCRMs bi-model, the experts choose certain vectors on $O N$ state and others are $O F F$ state. If we have chosen many vectors as $O N$ state at the input level, the resultant vector will have two many $1 \mathrm{~s}$ as on $O N$ state. There is no specific criteria or framework laid down to guide the experts while choosing the input vectors. To avoid this problem, IFCMs model predicates the appropriate results when comparing with FCRMs model. There are many advantages of IFCRMs model over FCRMs model.

1) Each vector is given its due importance by keeping it ON state.

2) The impact of all attributes are gathered into one induced bi-graph for the final analysis.

In the process it is possible to detect the interrelationship between the attributes and how one influences the other while reaching the equilibrium state.

The fixed point obtained will include the impact of all the mentioned attributes and the interpretation of the results will be complete solution rather than partial solution.

\section{CONCLUSION}

In this section we have discussed employee--employer relationship which are evolved through IFCRMs method. The above discussed algorithm of the given problem focussed on the node that $X_{1} X_{5}$ and $X_{12}$ which play role of fixed point and $X_{2}$ (only pay to the employee), $X_{3}$ (pay with allowance (or bonus) to the employee), $X_{4}$ (best performance), $X_{5}$ (average performance), $X_{7}$ (employee works more number of hours), $X_{9}$ (maximum profit to the industry), $X_{15}$ (good relation between employee and employer), $X_{16}$ (demand of the employee which is not fulfilled) are the major factor of this relationship. Similarly for the FRMs model $D_{3}, D_{9}, D_{13}$ play role of fixed point and $R_{4}$ (structure work condition), $R_{5}$ (reward to the employee who are loyal to the organization), $R_{8}$ (good relationship of manager with other employees), $R_{3}$ (linked rewards and benefits to fulfilling job requirement), $R_{6}$ (Provide opportunities for employee to develop technical skill), $R_{7}$ (achievement of the industry), $R_{2}$ (reinforce the need to follow organization policies and practice) are the major factors of this relationship. To increase strong employer employee relations in an any industry they should follow some remedial measures which are discussed in below:

1) Strong employment relations create a pleasant atmosphere within the work environment; its increase the employee motivation. Companies that have invested into employee relations programs have experienced increase in the productivity and therefore the increased productivity leads to increase in profits for the industry.

2) Creating the productive and pleasant work environment has a drastic effect on an employee's loyalty to the business; it encourages a loyal workforce. Having such workforce improves employee retention.

3) When a work environment is efficient and friendly, the extent of conflict within the workplace is reduced. Less conflict results in the employees being able to concentrate on the tasks at hand and they are therefore more productive.

4) Employer always motivate their employee through encouragement and incentives. It is known throughout all levels of management that happy employee make productive employees.

5) When creating a work environment with a an effective communication network there is one key factor i.e. employer's always keep their door open. Maintaining an open channel of communication will solve the problems quickly, which is beneficial for quick resolution.

6) Most employers aren't into equality as they would like to believe they are. But by embracing equality for all employees will create a fair and equal workplace environment for all. If every employee feels equal and important they are more likely to work harder and be more productive.

\section{ACKNOWLEDGMENT}

The author would like to express their gratitude to all the referees for their valuable comments.

\section{REFERENCES}

[1] A. V. Devadoss and M. C. J. Anand, "Dimensions of Persnality of Women in Chennai using CETD Matrix", International Journal of Computer and Applications (ISSN 0975-8887), vol. 50, no. 5, pp. 10-17, July, 2012.

[2] M. C. J. Anand and A. V. Devadoss,"Application of Topsis method to analyze causes of suicide thought in domestic violence", International Journal of Computing Algorithm, vol. 2, pp. 354-362, October 2013.

[3] A. V. Devadoss and M. C. J. Anand, "A New Fuzzy Tool: Induced Cluster Method (ICM) to Study about Suicide Thought in Domestic Violence", International Journal of Computing Algorithm, vol. 02, pp. 463-473, December 2013.

[4] A. Prakash Praveen "Analysis of the problems faced by the rural disadvantaged persons with dis-abilities using new fuzzy bi-models, Ph.D. thesis, University of Madras, (2010).J. Clerk Maxwell, A Treatise on Electricity and Magnetism, 3rd ed., vol. 2. Oxford: Clarendon, 1892, pp.68-73.

[5] B. Kosko, Neural Networks and fuzzy systems,Prentice Hall, India, 1988 .

[6] D. Ghosh,, A. Pal," Using Fuzzy Cognitive Maps and Fuzzy Relational Maps to Analyze Employee-Employer Relationship in an Industry", 
International Journal of Marketing and Technology (ISSN 22491058), vol. 1, Issue 6, pp. 105-130, November 2011

[7] D. Ghosh,, A. Pal," Using Fuzzy Cognitive Maps and Fuzzy Relation Equation to Estimate the Peak Hours of the Day for Transport Systems", CIIT International Journal of Fuzzy Systems (ISSN 0974-9608) February 2012.

[8] D. Ghosh,, A. Pal,"Use of Fuzzy Relational Maps and Intuitionistic Fuzzy Sets to Analyze Health Problem of Agricultural Labourers", Annals of Pure and Applied Mathematics (APAM), ISSN 2279087X(P), 2279-0888 (Online), Vol 1, No. 1, pp. 1-10, November 2013.

[9] G. Klir and T. Folger, Fuzzy sets, uncertainty and information, Prentice Hall, New Jersey, 1998.

[10] K. Balasangu, K. Thirusangu and V. Dare Rajkumar, "A fuzzy approach on the analysis of health hazards faced by the agriculture labourers due to chemical pollutions, Proc, of the Indian Conf. on Intelligent Systems Allied Publ. 123-128,2007.

[11] K. Balasangu , K. Thirusangu and V. Dare Rajkumar, On the health hazards of the rice cultivators using IFRM model . Int. J. Analyzing Methods of Components \& Combinatorial Biol. in Mathematics (IJAMCCBM), 1(1),1-10,2009.
[12] K. Balasangu, K. Thirusangu and V. Dare Rajkumar, IFAM model approach on the impact of pesticide on agricultural labourers, Indian J. Sci. Technol., vol. 4, pp. 151-154,2011.

[13] k . Ponnivalavan, T. Pathinathan, " The Study of Symptoms of Tuberculosis Using Induced Fuzzy Cognitive Maps (IFCMS)" IndoBhutan International Conference On Gross National Happiness, vol. 02, pp. 237-241, October 2013,

[14] R. Axelord, Structure of decision: The cognitive maps of political elites, Princeton, NJ: Princeton University Press, (1976).

[15] R.Kamala, Personality Medicine Model using Fuzzy Associative Memories, Masters Dissertation, Guide: Dr. W. B. Vasantha Kandasamy, Department of mathematics, Indian Institute of Technology, (2000).

[16] S. Narayanamoorthy, S. Kalaiselvan "Adaptation of Induced Fuzzy Cognitive Maps to the Problems Faced by the Power Loom Workers", I.J. Intelligent Systems and Application, vol. 9, pp. 75-80.2012.

[17] W.B. Vasantha Kandasamy and Florentin Smarandache, "Analysis of Social aspects of Migrant labourers living with HIV/AIDS using Fuzzy Theory and Neutrosophic Cognitive Maps", Xiquan, Phoenix, 2004.

[18] W.B. Vasantha, and T. Pathinathan, "Linked Fuzzy Relational maps to study the relation between migration and school dropouts in TamilNadu". Ultra. Sci.17, 3(M), pp. 441- 465, 2004. 